
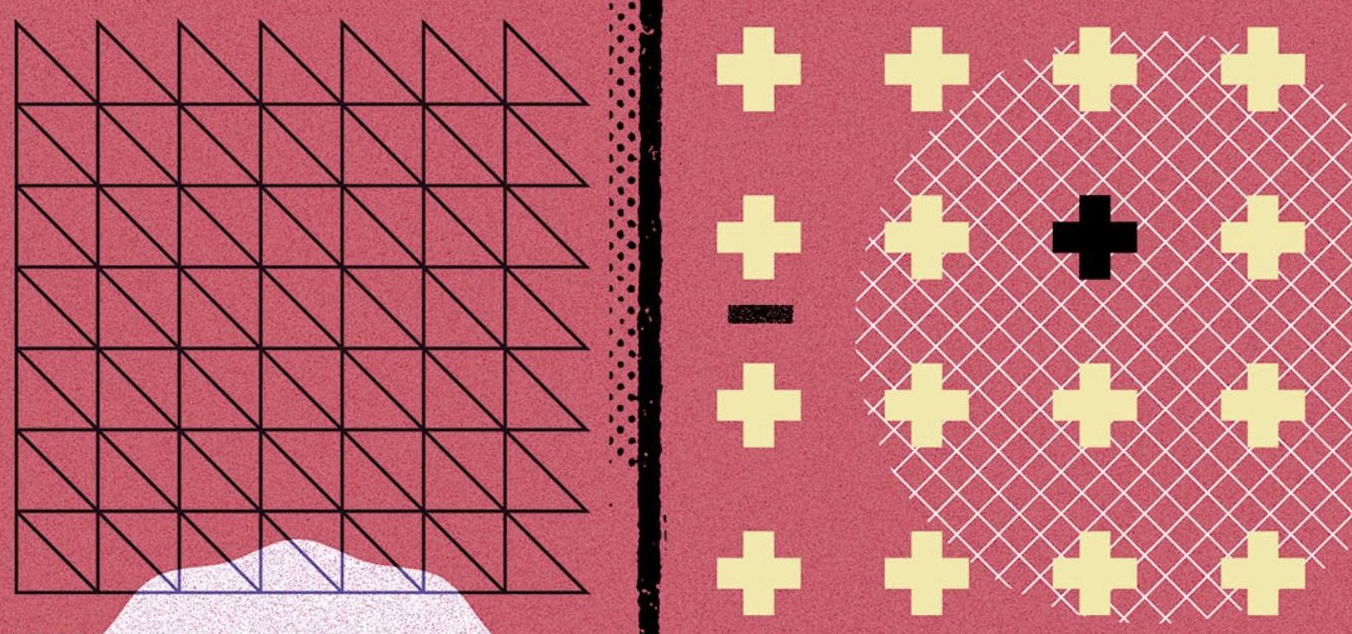

$\because \because \because \because \because \because \because \because \because \because \because \because \because \because \because \because \because \because$
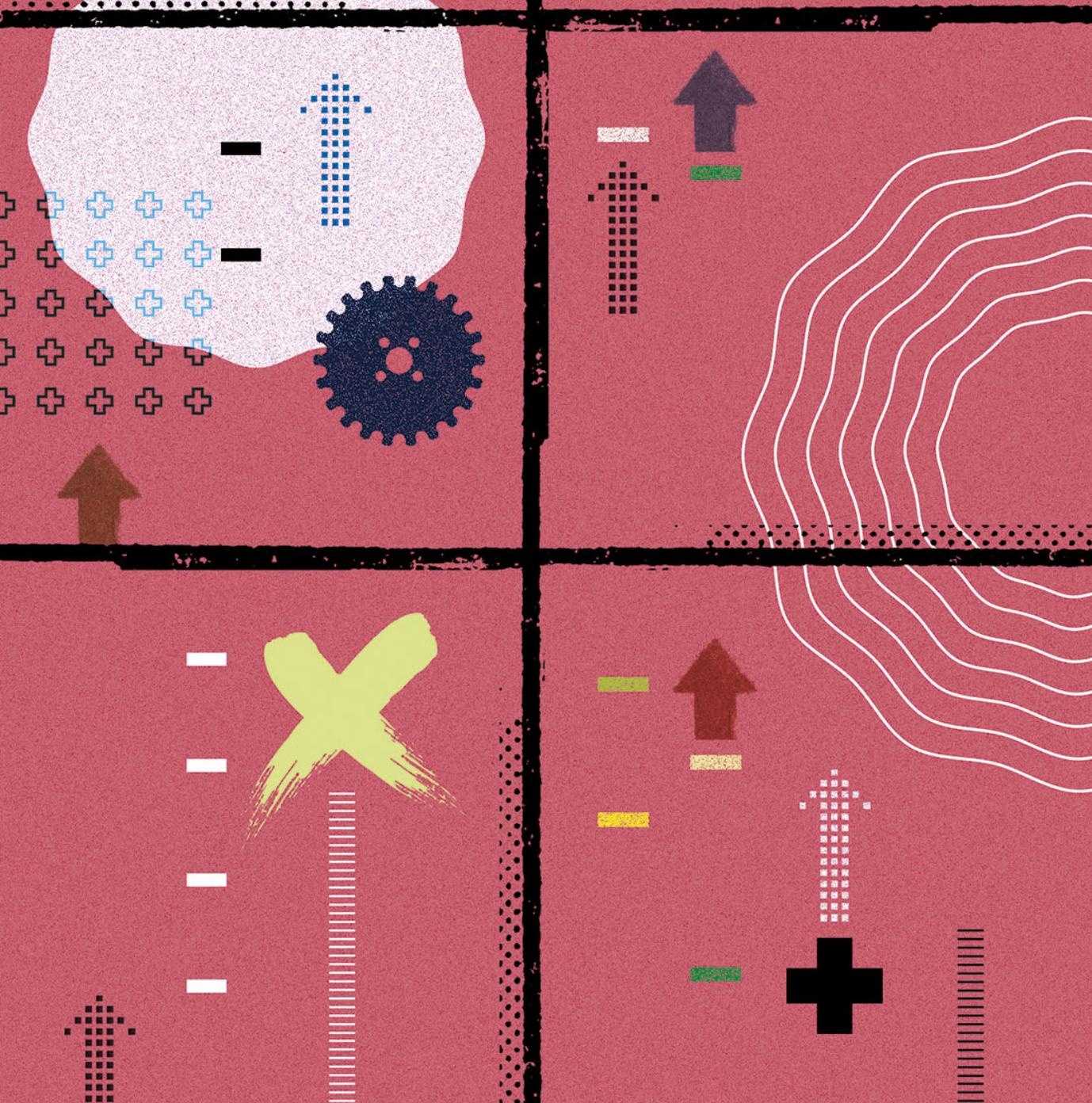


\title{
Limites para institucionalização de uma estratégia nacional de desenvolvimento no Brasil: uma análise das propostas "novo" e "social" desenvolvimentistas
}

\author{
Limits for institutionalizing a national \\ development strategy in Brozil: An analysis \\ of "new" and "social" development proposals
}

\author{
Herton Castigline Lopes* \\ Octávio Augusto Camargo Conceição** \\ Adriano José Pereira***
}

\begin{abstract}
Resumo
O trabalho objetiva discutir a dificuldade de institucionalização de uma estratégia nacional de desenvolvimento no Brasil. A partir do conceito de instituições presente nas abordagens institucionalistas, observa-se que a institucionalização de uma estratégia novo ou social desenvolvimentista foi comprometida pelos problemas macroeconômicos que vêm prejudicando a indústria, principalmente a de maior conteúdo tecnológico. Sugere-se que os governos do Partido dos Trabalhadores (PT) procuraram estabelecer uma estratégia social desenvolvimentista, mas não conseguiram superar os problemas estruturais, de regulação e da indústria nacional, que vem sofrendo graves prejuízos ao longo dos últimos anos.
\end{abstract}

Palavras-Chave: Institucionalismo; Estratégia Nacional de Desenvolvimento; Novo desenvolvimentismo; Social Desenvolvimentismo.

\begin{abstract}
This paper aims to discuss the difficulty of institutionalizing a national development strategy in Brazil. From the concept of institutions present in institutionalist approaches, it is observed that the institutionalization of a "new" or "social" strategy developmentalist has been compromised by the macroeconomic problems that have been harming the industry, especially the one with a higher technological content. It is suggested that Partido dos Trabalhadores (PT) governments have sought to establish a social strategy of development, but have failed to overcome the structural, regulatory and national industry problems, that has been suffering serious damage over the past few years.
\end{abstract}

Keywords: Institutionalism; National Development Strategy; New developmentalism; Social Developmentalism.

\footnotetext{
* Professor do Programa do Programa de Pós-Graduação em Desenvolvimento e Políticas Públicas da UFFS. https://orcid.org/0000-0003-3539-1729.E-mail: herton.lopes@uffs.edu.br.

** Professor do Programa de Pós-Graduação em Economia da UFRGS. https://orcid.org/0000-0002-3042-4555. E-mail:00000613@ufrgs.br

*** Professor do Programa de Pós-Graduação em Economia e Desenvolvimento da UFSM. https://orcid.org/0000-0002-9467-6516.E-mail: adrianoeconomia@ufsm.br.
} 


\section{INTRODUÇÃO}

Mesmo com o risco de uma simplificação exagerada, pode-se dizer que existiram duas propostas desenvolvimentistas para o Brasil ao longo dos últimos anos: o novo-desenvolvimentismo e o social-desenvolvimentismo (BASTOS, 2012; BRESSER-PEREIRA, 2012b). Ambas concordam com a necessidade de mudanças macroeconômicas, mas, divergem quanto à prioridade de política. Por um lado, a proposta do novo desenvolvimentismo indica que a dinâmica de crescimento deve priorizar a competitividade da indústria no exterior. Para isso, essa corrente coloca a taxa de câmbio como elemento central de sua proposta (BRESSER-PEREIRA, 2012) ao mesmo tempo em que supõe a atualização de muitas teses defendidas no desenvolvimentismo original, identificado com o processo de substituição de importações (PSI) no Brasil. Por outro, o projeto social desenvolvimentista, com um corpo teórico incipiente e fragmentado, defendeu a prioridade de políticas sociais e a distribuição de renda como forma de ampliar o mercado interno e crescer com base na diversificação produtiva. Enquanto a primeira corrente centra seus esforços em demonstrar a eficácia de um crescimento export-led, a segunda argumenta em prol de um modelo a la wage-led'.

A proposta desse texto é discutir os fatores que limitaram a institucionalização tanto de uma estratégia novo como social desenvolvimentista. Mais do que um conjunto de regras formais, as instituições representam acordos coletivos, alicerçados em hábitos, crenças, costumes, etc, que balizam e sustentam determinados comportamentos individuais. Quanto às duas estratégias, demonstra-se que sua dificuldade de institucionalização decorre dos muitos problemas estruturais e de política econômica que prejudicaram e ainda comprometem a emergência de acordos coletivos capazes de colocar a indústria e o progresso técnico como eixos dinâmicos do processo de desenvolvimento. Ainda que os governos do Partido dos Trabalhadores (PT) tenham priorizado uma política distributiva, que trouxe avanços nada desprezíveis do ponto de vista social, não conseguiu recuperar a estrutura produtiva, cujo desempenho se tornou um empecilho à continuidade das políticas que objetivaram maior equidade.

Para atingir a proposta de trabalho utilizam-se as definições de instituições presentes nas principais abordagens institucionalistas, a saber: o institucionalismo de Veblen com as abordagens recentes, da Nova Economia Institucional (N.E.I.), o institucionalismo da Escola da Regulação e a proposta neoschumpeteriana que, além de um forte apelo institucionalista, demonstra ser o desenvolvimento dependente do estágio de evolução das técnicas produtivas. Ainda que as abordagens sejam conflitantes em alguns pontos, observa-se que as teorias trazem contribuições relevantes para o entendimento da natureza das instituições e ajudam a compreender os motivos que dificultam a institucionalização de uma estratégia consistente.

Com vistas a atingir o objetivo proposto, a seção 2 sistematiza de forma breve a concepção de instituições nas diversas abordagens institucionalistas, demonstrando 
sua importância para o desenvolvimento. A seção seguinte apresenta a proposta do novo desenvolvimentismo, priorizando os problemas estruturais e de política econômica que, segundo essa corrente, prejudicam uma proposta de crescimento exported led. A seção 4 ocupa-se do social desenvolvimentismo e suas recomendações de política econômica centradas na questão distributiva e no crescimento do mercado interno. Finalmente, na seção 5 argumenta-se sobre os limites para a institucionalização das estratégias novo e social desenvolvimentistas. Na seção 5 apresentam-se as considerações finais.

\section{AS INSTITUIÇÕES E O DESENVOLVIMENTO: BREVES CONSIDERAÇŌES}

Como é comum na literatura econômica, que nem sempre encontra consenso nas suas proposições teóricas, o conceito de instituições varia de acordo com a abordagem e seu enfoque metodológico. No entanto, são identificadas algumas abordagens institucionalistas cujo conceito de instituição e seu efeito sobre o desenvolvimento merece ser considerado.

$\mathrm{O}$ institucionalismo original remete a uma diversidade de autores, tendo como um dos maiores expoentes T. B. Veblen. Sua critica a abordagem tradicional foi flagrante ao considerá-la demasiadamente estática, abstrata e pouco consistente no entendimento da natureza humana. Veblen (1989) propôs que seria mais importante explicar a mudança econômica, que acontecia com mudança institucional, do que encontrar pontos de repouso como advoga a teoria neoclássica. Ainda que a análise do autor não remeta diretamente ao desempenho econômico, ao observar que as instituições influenciam e são influenciadas pela forma como as pessoas produzem e reproduzem suas condições de vida, o autor não deixou dúvidas de que as instituições desempenham importante papel no processo de crescimento. Em Veblen (1919) as instituições são caracterizadas como hábitos compartilhados de pensamento. São eles que sustentam as instituições sociais, balizando comportamentos que afetam e são moldados pelo processo produtivo das sociedades.

Embora boa parte dos avanços feitos no campo de estudo das instituições se deva aos contemporâneos de Veblen, recentemente a teoria institucionalista voltou a ser preocupação de uma gama significativa de autores. Em 1993, Douglass C. North foi laureado com o Nobel ao explicar o desempenho das nações a partir de sua matriz institucional. Junto como R. Coase e O. Williamson, North compõe o núcleo teórico da N.E.I. A essência dessa escola está em analisar as firmas e o desempenho econômico a partir dos custos de transação existentes na utilização dos mercados².

Ainda que Douglass North tenha demonstrado como os modelos mentais influenciam na formação das instituições (NORTH, 2005; NORTHE DENZAU, 1994) uma análise mais consistente do papel da cognição humana na emergência de diferentes matrizes institucionais aparece em autores que recuperam os ensinamentos 
de T. Veblen. As instituições passam a representar mais que restrições ao comportamento individual estando constituídas de hábitos, crenças, valores, etc. Hodgson (2006; 2010), por exemplo, define instituições como um sistema de regras sociais estabelecidas e enraizadas na sociedade. Tais regras, contudo, existem justamente porque estão alicerçadas em elementos cognitivos, estando no hábito a chave para entendimento de como esse enraizamento ocorre e se mantém por períodos consideráveis de tempo.

Os hábitos são o elemento que oferece sustentação às instituições e podem ser tratados como o elo de ligação entre o ambiente micro e macroeconômico, superando a proposta de tratar os fenômenos econômicos a partir de pontos de equilíbrio que não explicam a mudança. Viabilizam, como reconhece a Escola da Regulação (E.R.), o funcionamento de um modo de produção essencialmente contraditório, permitindo, através de acordos coletivos, a manutenção dos conflitos dentro de limites compatíveis com a acumulação de capital. Nos regulacionistas o conceito de regulação refere-se justamente às mediações institucionais que mantém a coesão social, a coerência macroeconômica (AGLIETTA, 1976) e o crescimento; que acontece quando as instituições permitem que as divergências fiquem dentro de limites aceitáveis. Tal modo de regulação permite a emergência de um regime de acumulação específico, este entendido como as regularidades que asseguram a acumulação de capital (BOYER, 1990, p. 72). Entre o regime de acumulação e a regulação encontra-se a noção de formas institucionais, caracterizadas a partir da forma Estado; da forma concorrência; da gestão salarial; da forma de inserção do país no regime internacional e da gestão monetária.

Nos regulacionistas, o crescimento econômico resulta da configuração das formas institucionais, responsáveis por canalizar as regularidades do ambiente de atuação dos indivíduos para o plano macroeconômico, o que garante a convergência dessa escola de pensamento com o institucionalismo de Veblen (c.f. BRUNO, 2004). A escola ainda alinha-se aos institucionalistas neoschumpeterianos ao reconhecer que o crescimento econômico acontece com a incorporação do progresso técnico e que a configuração macroeconômica deve ser consistente no sentido de não bloquear a evolução das técnicas produtivas (CORIAT \& DOSI, 2007).

Partindo de Schumpeter $(1911 ;$ 1942) os neoschumpeterianos imputam as instituições o papel de estimular (ou restringir) a inovação e o avanço das técnicas produtivas. Tais referências normalmente são encontradas na literatura sobre os Sistemas Nacionais de Inovação (S.N.I.). Nelson (2007), por exemplo, define um S.N.I. como um conjunto de instituições ${ }^{3}$ que apoiam e orientam a dinâmica da atividade econômica e da inovação. Já em Pérez (1992) um sistema nacional de inovação deve manter relação com o plano microeconômico ao proporcionar esquemas de comportamento que, alicerçados nas instituições, viabilizam uma interação adequada das diversas organizações. 
Tratando da experiência asiática, essa escola de pensamento ainda observa como os países menos desenvolvidos podem alavancar seu catching up, reduzindo as diferenças de desenvolvimento que os separam das nações avançadas. Mais do que enfatizar a importância da indústria, os neoschumpeterianos observam que as oportunidades de desenvolvimento para os países periféricos dependem do estágio de evolução da revolução tecnológica em curso (FREEMANN \& PEREZ, 1988). Para os países menos desenvolvidos, internalizar as técnicas produtivas num momento de dupla oportunidade tecnológica, exatamente quando uma revolução entra em fase de maturação e outra começa a surgir, é o que permite atingir o "alvo móvel" do desenvolvimento (PEREZ, 1991), incorporando o novo paradigma tecnoeconômico ${ }^{4}$ justamente num momento estratégico da história.

Seguindo a analogia kuhniana (KUHN, 1992) a teoria neoschumpeteriana identifica que a propagação dos paradigmas produtivos resulta de inovações radicais. A atual revolução tecnológica (da microeletrônica) teve início nos anos 1970 com o anúncio do processador Intel em Santa Clara, Califórnia. Segundo o modelo Freemann-Perez (1988), o desenvolvimento depende de como países em desenvolvimento se inserem na revolução em curso, pois no atual estágio de desenvolvimento tecnológico o catching up depende da incorporação da tecnologia da informação e comunicação ao setor produtivo.

Finalmente, embora a tecnologia nem sempre apareça como primeira preocupação em algumas abordagens, como em Veblen, é fato que ela se define e é definida pela forma como as instituições evoluem sendo praticamente impossível compreender o estágio de desenvolvimento dos países sem observar a coevolução entre tecnologia e instituições (c.f. NELSON \& SAMPAT, 2001). Nessa perspectiva, uma estratégia nacional de desenvolvimento deve ser aquela que estimule os investimentos produtivos e o progresso técnico a partir de um conjunto de acordos que precisam ser muito mais do que simples restrições formais como demonstram os defensores da N.E.I. São necessários entendimentos coletivos, o compartilhamento de hábitos e rotinas, enfim, uma forma de regulação (formas institucionais) que esteja em confluência com os modelos cognitivos individuais. Estes precisam se tornar compartilhados pela sociedade oferecendo consistência ao sistema de regras da estratégia de desenvolvimento. A regulação, e seu conjunto de instituições socioeconômicas, devem estimular o progresso técnico, que precisa alinhar-se ao paradigma tecnoeconômico vigente de forma a viabilizar o catching up. Caso se trate de uma nação de industrialização retardatária, o desenvolvimento torna-se um objetivo a ser perseguido a partir de uma estratégia nacional, como demonstram as várias trajetórias das economias desenvolvidas (CHANG, 2004; MAZZUCATTO, 2014). Portanto, desenvolvimento é um processo path dependent, que requer a institucionalização de práticas que viabilizam objetivos comuns. 


\section{O NOVO DESENVOLVIMENTISMO: ÊNFASE NA TAXA DE CÂMBIO E UM CRESCIMENTO PUXADO POR EXPORTAÇŌES}

Partindo do desenvolvimentismo daCEPAL, maisespecificamente da sistematização apresentada em Bielschowsky (1988), o esforço inicial de Bresser-Pereira e outros autores foi promover uma atualização dos problemas estruturais das economias menos desenvolvidas. Não vamos reproduzir as teses que o novo desenvolvimentismo considera válidas (mesmo que com modificações), as que são abandonadas e as novas argumentações, ainda que a maioria delas apresentem-se inevitavelmente ligadas às exposições feitas ao longo dessa seção. A principal preocupação dos autores que seguem essa corrente teórica se refere à falta competitividade da indústria no mercado internacional, elemento decorrente da tendência cíclica de sobrevalorização da taxa de câmbio.

O novo desenvolvimentismo considera superada a estratégia de substituição de importações e pressupõe que o catching up dos países menos desenvolvidos resulta do preço que regula as transações da nação com o resto do mundo. Como Bresser-Pereira (2007a) considera o processo de globalização irreversível, o novo desenvolvimentismo mostra que um país menos desenvolvido, como o Brasil, precisa definir um câmbio competitivo para as empresas nacionais concorrerem, em condições de igualdade, com as firmas do resto do mundo. Uma das suas hipóteses básicas é de que os países de renda média já possuem uma indústria em condições de igualdade às demais, tendo o câmbio como principal empecilho para ampliar suas exportações líquidas ${ }^{5}$.

Argumentando sobre a importância do câmbio para o desenvolvimento, BresserPereira (2010; 2012a; 2014a; 2014b) prevê a possibilidade de duas taxas de equilíbrio. Chama de equilíbrio corrente aquela com a qual é possível equilibrar a balança comercial, ainda que se imponham sérios prejuízos a indústria exportadora, e qualifica como taxa de câmbio de equilíbrio industrial aquela que oferece à manufatura nacional condições de competir no mercado externo. A primeira resulta da exploração dos recursos naturais e tende a ser sobreapreciada. A segunda é aquela que viabiliza a concorrência quando as empresas utilizam a tecnologia no estado da arte mundial.

Nas nações de renda média, os desequilíbrios do Balanço de Pagamentos não são piores graças ao crescimento ancorado em recursos naturais. Atuando em conjunto com a doença holandesa ${ }^{6}$, a absorção de poupança externa é referenciada como outra causa importante da apreciação da moeda doméstica. Antes apontado como uma das principais fontes de financiamento para os países subdesenvolvidos, esse tipo de recursos agora é tido como um entrave ao catching up das nações menos desenvolvidas. Para Bresser-Pereira e Gala (2010) e Bresser-Pereira (2007; 2014a), esse fluxo de recursos causa endividamento externo, instabilidade financeira e não tem grande influência sobre os investimentos produtivos. A poupança externa acaba substituindo a poupança interna ${ }^{7}$ porque age valorizando a moeda nacional, incentivando importações, prejudicando a expectativas de lucros dos empresários 
nacionais, desestimulando a formação bruta de capital fixo e a geração de poupança nacional, que acontece ex post segundo a tradição keynesiana, reivindicada pelo novo desenvolvimentismo.

A atração de recursos do exterior ainda é reflexo da política macroeconômica. A gestão monetária, com prioridade no controle da inflação acaba incentivando um grande fluxo de recursos especulativos responsáveis por grandes vulnerabilidades cambais e crises financeiras. Tanto o câmbio como os juros são utilizados prioritariamente para conter os preços altistas, mesmo que uma boa parte das pressões inflacionárias seja de custos ou estruturais. Cabe reiterar que o novo desenvolvimentismo não se posiciona contra políticas de estabilidade. Ao contrário das ideias desenvolvimentistas originais, que admitiam crescimento com inflação ascendente, o novo desenvolvimentismo argumenta sobre a necessidade de crescimento com uma inflação relativamente sobre controle, embora ela possa ser mais elevada que nos países desenvolvidos ${ }^{8}$.

Ainda que defendam uma atuação mais tímida do setor público, a importância dessa instituição continua expressiva. Muitos escritos de autores novo-desenvolvimentistas chamam atenção para o papel do Estado na definição de uma correta estratégia nacional. Em texto precursor, Bresser (2007b) chamou a estratégia nacional de instituição chave do desenvolvimento econômico. Demonstrou clara-mente que o desenvolvimento só pode ser alcançado quando se constituem os estados nacionais e estes passam a congregar as diferentes classes em um pensamento comum. BresserPereira e Theuer (2012) afirmam que a participação do Estado deve ser ampla o suficiente para viabilizar uma estratégia de desenvolvimento (uma instituição informal) que congregue valores, objetivos, políticas, leis, etc. Trata-se de uma estratégia de coesão social capaz de proporcionar compromissos que criem oportunidades de investimento e melhoram as condições de vida da população.

Quanto à questão distributiva, inicialmente o novo desenvolvimentismo chega a afirmar que os países de industrialização retardatária sofreriam com um antigo problema destacado pela CEPAL (BRESSER-PEREIRA \& GALA, 2010): o fato de os salários crescerem abaixo do ritmo de produtividade. No entanto, ao perceberem o possível conflito entre uma distribuição mais equitativa e a ênfase exportadora (uma vez que maiores possibilidades de consumo poderiam demandar valorização da moeda nacional) os adeptos do novo desenvolvimentismo tomam partido de uma política cambial ativa. Embora as desvalorizações iniciais tendessem a reduzir o poder de compra das classes menos favorecidas, no longo prazo a questão distributiva poderia ser melhorada pelas oportunidades de investimento decorrentes de uma taxa de câmbio mais competitiva. A onda de crescimento abriria espaço para políticas efetivas de salário mínimo e melhorias sociais que poderiam ser obtidas com uma estrutura tributária progressiva (BRESSER-PEREIRA, 2014b).

Portanto, o novo desenvolvimentismo claramente subordina questões sociais e distributivas à melhor performance das indústrias exportadoras. Embora essa visão 
não estivesse explicita nas propostas originais, acessar a demanda (BRESSER-PEREIRA, 2014c) mediante uma taxa de câmbio adequada aparece como elemento fundamental dessa proposta. Deter a sobrevalorização cíclica da taxa de câmbio, estimulando as exportações, seria essencial para aumentar os investimentos dado que uma moeda nacional valorizada serviria apenas para aumentar o consumo, ampliando o déficit em conta corrente que seria contrabalançado pelas exportações primárias e poupança externa.

\section{O SOCIAL DESENVOLVIMENTISMO E A PROPOSTA DE CRESCIMENTO DISTRIBUTIVO}

Diferentemente da abordagem novo-desenvolvimentista, o social desenvolvimentismo não apresentou um corpo teórico bem definido, sendo muito mais fruto de ideologias partidárias e proposições políticas que começam a ganhar espaço no início desse século?.

À semelhança do novo desenvolvimentismo, o social desenvolvimentismo preocupase com alguns problemas levantados pelo desenvolvimentismo original. A maior equidade social, principal pilar dessa proposta, sempre foi uma das grandes bandeiras dos desenvolvimentistas cepalinos. Embora muitos economistas e cientistas sociais a defendessem de forma inequívoca, o modesto avanço dos países da América Latina foi comprovado por Fajnzylber (2000) ao concluir sobre a dificuldade de se conciliar um crescimento sustentado com políticas efetivas de distribuição de renda. O próprio Celso Furtado (2004), pouco antes de seu falecimento, argumentou ser o desenvolvimento distinto do crescimento justamente pelo caráter social do primeiro conceito. A questão da equidade chamou tanta atenção que a própria agenda da CEPAL enfatizou a necessidade de políticas efetivas para corrigir as distorções sociais causadas pelo processo de substituição de importações ${ }^{10}$.

Após a onda neoliberal do final do século passado, a distribuição de renda passou a ser uma das maiores preocupações da política econômica. A ideologia social desenvolvimentista ${ }^{11}$ reconhece que não existe desenvolvimento sem que sejam equacionados diversos problemas sociais. Por isso, canaliza para o Estado a responsabilidade de promover uma política de rendas, seja mediante valorização do salário mínimo ou através de benefícios sociais. Enquanto o desenvolvimentismo original deixou em segundo plano a inclusão dos trabalhadores, o social desenvolvimentismo estaria tentando atender determinados extratos sociais historicamente excluídos, reconhecendo a luta de classes presente em uma econômica capitalista (IANONI, 2014) ${ }^{12}$. Propõe um fortalecimento do mercado interno mediante políticas de maior equidade, mas, dessa vez, evitando-se surtos inflacionários, endividamento público e déficits crônicos (MANTEGA, 2007; COSTA; 2012; 2015; POCHMANN, 2012).

A prioridade de um crescimento puxado pelo consumo interno se justifica pelas supostas potencialidades da economia brasileira. Ao contrário dos países asiáticos, onde predomina a estratégia exportadora, na visão social desenvolvimentista o país 
teria um potencial de diversificação produtiva sem precedentes, bastando políticas distributivas capazes de aquecer a demanda interna. Mollo e Amado (2015), por exemplo, arrolam uma diversidade de argumentos para defender a estratégia social desenvolvimentista como mais adequada. Além de ser mais justa do ponto de vista social, observam que a estratégia distributiva pode estimular a dinamicidade do setor industrial sem inibir os lucros, aumentando, assim, os investimentos que seriam dinamizados pela maior demanda ${ }^{13}$.

Embora tais argumentos sejam coerentes tanto do ponto de vista social como econômico, no final da década passada a estratégia parecia ineficaz em manter o ritmo de crescimento. Contrapondo-se ao suposto estancamento do modelo, alguns trabalhos argumentaram que ainda existiria possibilidade de crescimento intensificando o consumo popular. Bielschowsky (2012) demonstrou que a estratégia de desenvolvimento para Brasil deveria continuar pautando-se pelos investimentos induzidos pelo consumo em massa, mas apoiados por políticas destinadas a setores especializados em recursos naturais e infraestrutura. A inovação tecnológica e a reativação de encadeamentos produtivos tradicionais agiriam como "turbinadores" dessa proposta. Costa (2015) fala de investimentos que possuem encadeamentos para frente e para traz como nos casos de serviços (educação, saúde, banda larga, etc) e indústria (trem bala, ferrovias, etc). Seus argumentos ainda remetem aos incentivos à construção (mobilidade urbana, urbanização de favelas, saneamento, moradia popular, etc.), a indústria extrativa, a agroindústria (complexo da soja, biodiesel, sucroalcooleiro, carnes, etc) e a indústria de transformação. Para Carneiro (2012), além da distribuição da renda, seria prioridade a ampliação da infraestrutura econômica e social, a reindustrialização via adensamento das cadeias produtivas e a expansão do setor baseado em recursos naturais.

Embora um número considerável de autores lembrem a importância de serem atacados os problemas estruturais, a distribuição de renda mantém-se o "carro chefe" dessa proposta (CARNEIRO, 2012). Para Kerstenetzky (2015, p. 2) isso se justifica pelo nosso problema histórico de desigualdade, que colocou o projeto social desenvolvimentista como a única proposta interessante e socialmente aceitável dado o momento histórico ${ }^{14}$. Argumenta que o crescimento distributivo pode ser intensificado se consideradas as brechas de consumo discricionário (dado pela distância de consumo dos domicílios brasileiros em relação a um consumo típico da classe média), de consumo necessário, que se refere aos indivíduos sem recursos para satisfazer as suas necessidades básicas (uma população entre 17 e 57 milhões de pessoas) e de bens públicos sociais ${ }^{15}$.

Quando comparada ao novo desenvolvimentismo, a proposta social desenvolvimentista se distingue essencialmente pela prioridade de política econômica. Adeptos desta última criticam o novo desenvolvimentismo justamente pela excessiva ênfase no poder das políticas macroeconômicas (câmbio, juros, inflação, etc). À exceção da forma de condução da política fiscal, não discordam dos problemas apresentados 
por tal abordagem, mas criticam a prioridade essencialmente exportadora (exportled) de Bresser-Pereira e seus seguidores. Os sociais desenvolvimentistas advogam que intensificar a competitividade das empresas via câmbio poderia trazer sérias consequências para a distribuição; prejudicando as condições de vida dos menos favorecidos. Supõem que países como o Brasil possuem um regime de crescimento prioritariamente a la wage-led e políticas distributivas que aumentem os salários, a demanda e o mercado interno seriam mais eficientes, proporcionando um crescimento mais igualitário do que a promoção das exportações ${ }^{16}$.

\section{SOBRE OS LIMITES DE INSTITUCIONALIZAÇÃO DAS ESTRATÉGIAS DE DESENVOLIMENTO}

Uma das questões mais importantes que permeia o institucionalismo é a relação entre instituições e indivíduos. A perspectiva teórica do institucionalismo original com seus desdobramentos recentes observa que indivíduos e instituições possuem uma relação interdepende porque são os hábitos que formam as instituições ao mesmo tempo em que estas agem sobre as preferências, crenças, ações individuais, etc. Mais do que um conjunto de regras formais, como enfatiza a N.E.I., uma instituição desenvolvimentista precisa representar as crenças e os hábitos que emergem do plano microeconômico constituindo-se em uma estratégia promotora da coalizão de classes, amenizando os possíveis conflitos provenientes da interação entre pessoas. A estratégia de desenvolvimento deve ainda se manifestar em uma regulação capaz de tratar os problemas macroeconômicos a partir de formas institucionais que preservem a acumulação de capital e o progresso técnico que precisa da convergência de padrões comportamentais de indivíduos que atuam na esfera produtiva.

No caso brasileiro a estratégia de desenvolvimento dos últimos anos se mostrou prioritariamente social desenvolvimentista (OREIRO \& MARCONI, 2016). O melhor desempenho econômico dos anos $2000^{17}$ e a prioridade social do Estado repercutiram em uma diversidade de indicadores. O desemprego caiu consideravelmente (em 2014 ficou próximo dos 5\% em algumas regiões metropolitanas, segundo IPEA, 2016), o rendimento médio real praticamente duplicou de 2001 a 2014 e a concentração de renda se retraiu (o índice de Gini, que girava em torno de 0,6 nos anos 1990, chegou a 0,53 em 2014). O melhor desempenho do mercado de trabalho e as políticas sociais $^{18}$ fizeram a pobreza retroceder. Ainda que significativo, o número de pessoas extremamente pobres, que chegou perto dos 29 milhões em 1992, estava em pouco mais de 10 milhões em 2012. Nesses, e outros argumentos, se justificam o adjetivo "social" utilizado por acadêmicos e políticos para se referirem ao período Lula e Dilma na presidência da república.

Depois do período de euforia, a debilidade do crescimento, a aceleração inflacionária e a ascensão do desemprego deram indícios da dificuldade de institucionalização de uma estratégia nacional consistente, apesar da canalização dos recursos públicos para 
ações "sociais". Embora o país tenha experimentado certa modificação na forma wage labour nexos, as principais dificuldades em termos de configuração macroeconômica, que deveriam canalizar hábitos produtivos às formas institucionais, se apresentaram na forma de inserção do país no regime internacional e na gestão monetária. Mesmo que uma prioridade social desenvolvimentista tenha logrado êxito considerável em atacar um dos principais problemas do Brasil, as políticas redistributivas são reféns de rígidas regras macroeconômicas.

Como uma cartilha da Nova Economia Institucional ${ }^{19}$, as regras de condução da política econômica mantiveram prioridade nas metas de inflação e de superávit primário, somadas a uma elevada abertura financeira e comercial. Ainda que o argumento seja o de "reduzir a incerteza" e agradar os mercados (reduzir custos de transação), a simples conjunção de regras formais não garante a institucionalização de uma estratégia cujo maior objetivo deveria ser o fortalecimento dos investimentos produtivo ${ }^{20}$. Mesmo amenizando os problemas inflacionários e de divisas ${ }^{21}$, essa forma de inserção internacional causa instabilidade cambial, deixa a economia vulnerável a crises financeiras e pressupõe uma política monetária restritiva, com altas taxas de juros que oneram o Estado e prejudicam sua própria estratégia de desenvolvimento que acaba comprometida pela falta de recursos e restrições de gastos. Além disso, limitam sobremaneira um planejamento de longo prazo por parte do setor privado no que se refere à produção.

Essa forma de regulação macroeconômica dificulta a institucionalização tanto da estratégia novo como da social desenvolvimentista. Estabelece a possibilidade de ganhos financeiro-especulativos que desestabilizam os hábitos produtivos, dificultando a criação de rotinas centradas no avanço tecnológico. Essa "inércia" institucional, herdada dos anos 1990, ainda estimula um crescimento pautado na exploração do setor primário, danoso ao desempenho da indústria nacional conforme esboçam o conjunto dos autores desenvolvimentistas. A esse respeito, a proposta do social desenvolvimentismo previa que políticas redistributivas capazes de aquecer a demanda abririam maiores oportunidades de investimento no mercado interno, dinamizando a indústria nacional. No entanto, a forma de regulação acaba incentivando vazamentos de renda a partir da importação de bens de consumo produzidos no exterior e que ganham competitividade devido à valorização da moeda que foi impulsionada pelo ingresso de divisas dos últimos anos ${ }^{22}$.

Não é um problema recente. Furtado (1974) já demonstrava que o consumo dos países subdesenvolvidos tendia a ser arquétipo dos países avançados. Uma forma de dependência que se propagava tanto em bens de capital como em bens de consumo que atendiam apenas uma pequena minoria da população. Por essa razão, uma política distributiva, mesmo que consistente, precisaria encontrar respaldo em uma forma de inserção internacional que evitasse o aumento de importações, substituindo-as por produção doméstica (c.f. CARNEIRO, 2012) e evitando pressões sobre as contas externas que só não são maiores devido à conta capital ${ }^{23}$ e a exportação de produtos 
tradicionais. Mesmo que o social desenvolvimentismo não concorde com a prioridade exportadora enquanto políticas tarifárias, de câmbio ou seletivas de importações não forem utilizadas, o consumo interno tende a ser financiado prioritariamente com poupança externa (como afirma Bresser-Pereira) e com altas taxas de juros que atraem o capital especulativo.

A indústria nacional é a maior prejudicada com essa forma de regulação (altas taxas de juros - atração de capital - valorização cambial - consumo improdutivo). Colocando-a como eixo central do desenvolvimento ${ }^{24}$ uma série de autores brasileiros tem enfatizado a debilidade da nossa estrutura produtiva. Muitos trabalhos vêm advogando que o Brasil sofre com um processo de desindustrialização precoce (CANO, 2015; GONÇALVES, 2012; OREIRO \& FEIJÓ, 2010, entre outros) que teve início ainda nos anos 1980 e se intensificou nos anos seguintes (AREND, 2015). O valor adicionado da indústria em relação ao total, que chegou a representar mais de 17\% em 2004, caiu consideravelmente nos anos que se seguiram. Em 2014 e início de 2015 vai para menos de 11\% (10,9\% em 2014 e 10,1\% no primeiro trimestre de 2015). Já o Valor da Transformação Industrial (VTI) em relação ao Valor Bruto da Produção Industrial (VBPI) - um indicador do adensamento das cadeias produtivas ${ }^{25}$ - vem declinando desde 1996. Era de 46,1\% em 1996 reduzindo-se para 42\% em 2003 e chegando a $38,7 \%$ em 2013. Desempenho diferente foi observado na indústria extrativa, pois a razão VTI/VBPI sobe de 1,2\% em 1996 para 1,4\% em 2003 e atinge o ápice de 6,1\% em 2013. No setor externo, a balança comercial de produtos não industriais passou de um déficit de 29 milhões no primeiro semestre de 1996 para um superávit de 31 bilhões no mesmo período de 2011. Segundo a Protec (2011), o valor percentual de algumas commodities selecionadas representava $29,10 \%$ do total de exportações brasileiras nos anos 2000, passando para algo em torno de 52\% no ano de $2010^{26}$. Enquanto o setor mais tecnológico convive com déficits exorbitantes (no ano de 2013 chegou a ordem de 93 bilhões, enquanto no ano de 2000 girava em torno 20 bilhões), o setor de baixo conteúdo tecnológico vem apresentando superávits crescentes (no primeiro semestre de 2006 era de quase 7 bilhões, passando para 20 bilhões no primeiro semestre de 2011).

O fraco desempenho industrial demonstra a necessidade de serem conciliadas políticas de maior equidade com uma adequada forma de regulação e estímulos setoriais que recuperem o desempenho da indústria brasileira. Uma estratégia nacional eficiente deve fazer distribuição de renda ao mesmo tempo em que ataca os problemas macroeconômicos e estruturais que atrofiam o setor produtivo ${ }^{27}$. Nesse sentido, no Brasil, na medida em que as políticas distributivas não encontram respaldo nas mudanças na estrutura produtiva, faz-se necessário um esforço crescente do Estado para resolver os problemas sociais. Caso contrário, o conflito distributivo decorrente da perda de dinamismo econômico precariza a coalizão social e o compartilhamento de hábitos individuais; fator essencial para o desenvolvimento econômico e para a estruturação de um modo estável de regulação. 
Para isso é preciso ir além das políticas keynesianas tradicionais. Ainda que as duas estratégias propostas coloquem ênfase na demanda efetiva, supor que a estrutura produtiva se torne avançada unicamente estimulando-se o consumo interno ou as exportações pode ser um equívoco porque normalmente a tecnologia não flui para as economias menos desenvolvidas com simples condições macroeconômicas favoráveis ou adequadas políticas distributivas. Junto com uma configuração macroeconômica menos restritiva devem ser postas em curso políticas efetivas de estimulo ao progresso técnico, o que significa dinamizar, sobretudo, a indústria de mais alto conteúdo tecnológico. Os ganhos de produtividade decorrentes são o melhor caminho para manter a coalizão nacional e viabilizar a institucionalização de uma estratégia coerente. Coriat e Dosi (2007), por exemplo, advogaram a necessidade das condições de demanda evoluírem em conjunto com as técnicas produtivas, permitindo a adequada absorção e distribuição dos ganhos de produtividade ${ }^{28}$. Nesse sentido, Cimoli et al (2017) observam que o processo de desenvolvimento tem sido mais eficaz, inclusive com melhor distribuição de renda, em economias em que a produtividade do trabalho avançou em conjunto com os gastos sociais. No caso brasileiro, à exemplo de outros países latino-americanos, o aumento dos gastos sociais ao longo da primeira década do século XXI não foi acompanhado pelos ganhos de produtividade, impondo limites à qualquer estratégia de desenvolvimento.

Observando a necessidade da correta definição dos preços macroeconômicos, por decorrência da configuração da forma wage labour nexos, Bresser-Pereira (2014a) observou que os salários devem crescer no ritmo da produtividade, principalmente quando o desemprego encontra-se baixo. Portanto, a forte absorção da força de trabalho no auge do crescimento dos anos 2000 revelou tão somente a necessidade de progresso técnico. Quando o nível de ocupação se torna elevado, a introdução de novas tecnologias, que ocorre principalmente nos setores industriais, é a chave para maiores níveis de produtividade, melhor distribuição de renda, coalizão nacional e um desenvolvimento mais democrático.

Nos neoschumpeterianos, operar com tecnologias avançadas significa a incorporação das tecnologias revolucionárias ao setor produtivo. Ainda que o novo desenvolvimentismo considere que a indústria brasileira opera num estado da arte (tecnológico) que se assemelha ao das nações avançadas, o desempenho do Brasil na revolução da microeletrônica ainda é pouco consistente. Estudos como os de Carneiro (2008) ${ }^{29}$ e Arend (2015) atestam o frágil desempenho brasileiro na revolução da microeletrônica. Enquanto nos EUA e Coreia do Sul o setor produtor de material eletrônico e de telecomunicações chega a representar, respectivamente, 52\% e 37\% da indústria de transformação no final da década de 2000, no Brasil, ficaram em torno de 3,4\% em 2012 (UNIDO, 2016).

Mudar esse cenário requer uma estratégia nacional de desenvolvimento que fortaleça o Sistema Nacional de Inovação e supere, ou amenize, os problemas de condução da política econômica, recuperando e desenvolvendo a indústria mais 
avançada tecnologicamente. Como observou Gonçalves (2012), referindo-se ao período de substituição de importações, uma estratégia desenvolvimentista requer certa subordinação de muitas políticas (estabilização, por exemplo) a metas de desenvolvimento ${ }^{30}$. Enquanto uma estratégia desse tipo não for posta em curso, sua institucionalização fica prejudicada porque a falta de crescimento desestabiliza o comportamento dos indivíduos, levando a constantes conflitos e a dificuldade de serem compartilhados hábitos e comportamentos individuais centrados na acumulação do capital e no progresso das técnicas produtivas. Mesmo que muitas regras sejam impostas com a intenção de dar transparência aos mercados, sua simples existência não garante o desenvolvimento, pois as normas podem ser direcionadas para um tipo de acumulação que não interessa à esfera industrial.

Tanto no escopo de trabalhos recentes, que estão procurando elucidar o conceito de desenvolvimentismo (ver FONSECA, 2014), como nas duas estratégias propostas para o Brasil contemporâneo ("novo" ou "social" desenvolvimentismo), observamse os limites e a dificuldade de institucionalização de uma estratégia nacional de desenvolvimento. Os problemas de regulação macroeconômica e estruturais, somados ao frágil desempenho da indústria, principalmente a de maior conteúdo tecnológico, atestam que a dificuldade de institucionalização de uma estratégia desenvolvimentista não é apenas um problema do Governo Dilma, conforme descreve Curado (2017). Trata-se de uma questão de longo prazo, cujas origens devem ser encontradas no próprio processo de substituição de importações, na crise dos anos 1980, nas reformas liberais dos anos 1990 e na ausência de uma política industrial consistente. Esta, aliás, deveria figurar como uma das maiores preocupações de qualquer estratégia de desenvolvimento. Foi o que propuseram Pereira e Dathein (2016) ao analisarem criticamente o novo desenvolvimentismo e concluiu Fonseca (2014), quando considera a industrialização como componente do núcleo teórico (core) desenvolvimentista.

Finalmente, cabe pontuar que as diversas abordagens institucionalistas reconhecem o caráter path dependence das instituições. Veblen observou a dificuldade de mudança institucional tratando de imbecil institutions, aquelas que resistem no ambiente socioeconômico mesmo causando os mais reconhecidos danos à sociedade. O próprio Douglass North, ainda que enfatizando a necessidade de regras transparentes para o funcionamento dos mercados, viu a possibilidade de algumas instituições premiarem os ganhos improdutivos de alguns grupos de interesse. No caso brasileiro, observa-se claramente o fenômeno path dependence na forma de regulação que prevalece desde os anos 1990. Romper com essa lógica rentistapatrimonial instituída na regulação vigente e colocar a indústria e o progresso técnico com eixos dinâmicos do crescimento é condição primordial para institucionalização de uma estratégia nacional na atualidade. 


\section{CONSIDERAÇÕES FINAIS}

A proposta desse texto foi discutir a dificuldade de institucionalização de uma estratégia de desenvolvimento para o Brasil. Claramente, os governos do PT optaram por uma política social desenvolvimentista, colocando a estratégia de maior equidade à frente de reformas institucionais que pudessem amenizar os problemas estruturais e macroeconômicos do país. Nessa perspectiva e sob o prisma teórico em debate, a institucionalização de uma estratégia nacional requer:

a) Uma convergência entre os hábitos mentais e as regras macroeconômicas, especialmente visando desencadear ações de investimento e inovação tecnológica.

b) Uma apropriada forma de regulação, entendida como aquela que proporciona redistribuição de renda e políticas de maior equidade em conjunto com uma adequada definição da forma de inserção do país no regime internacional, da forma de gestão monetária e da participação do Estado na economia.

c) Estímulos macroeconômicos e setoriais que permitam a internalização das técnicas produtivas mais avançadas, recuperando a indústria de maior conteúdo tecnológico.

d) Mais que um conjunto de restrições macroeconômicas, chegando-se a uma proposta que permita a coalizão social a partir da adequada definição dos preços macroeconômicos, evitando os conflitos sociais que prejudicam tanto a acumulação de capital como o progresso técnico.

A prioridade social desenvolvimentista foi bem sucedida enquanto o Brasil vivenciou elevadas taxas de crescimento, puxadas principalmente pela dinâmica do mercado mundial (boom das commodities e ciclo de liquidez internacional). No entanto, o período também foi marcado pelo pouco avanço da estrutura produtiva, que vem sendo prejudicada desde os anos 1980. A reversão do cenário internacional, a dificuldade em promover qualquer mudança estrutural e a crise política recente são elementos que ameaçam seriamente qualquer proposta de crescimento.

O grande mérito do social desenvolvimentismo foi propor uma estratégia de crescimento alicerçada no mercado interno, tentando corrigir o problema histórico de desigualdade existente no Brasil. Seu calcanhar de Aquiles foi justamente a dificuldade de modificar a estrutura produtiva em direção à indústria de maior conteúdo tecnológico. O novo desenvolvimentismo, por sua vez, coloca em primeiro lugar o tratamento de problemas macroeconômicos que impedem o desenvolvimento do país. O principal questionamento a sua proposta é, no entanto, o fato de deixar em segundo plano a questão distributiva, enfatizando muito mais a inserção competitiva da indústria no mercado internacional, o que poderia, inclusive, contrariar políticas distributivas de curto prazo. 
Ainda que a estratégia dos últimos anos tenha estipulado uma prioridade social, já se observam as dificuldades do não tratamento dos problemas crônicos que foram salientados por diversos autores, adeptos do novo e do social desenvolvimentismo. O baixo crescimento dificulta a promoção de políticas sociais, deprimindo o orçamento público e trazendo ao governo grandes dificuldades de implementar ações anticíclicas. Ao longo do processo de substituição de importações o Brasil procurou se aproveitar do auge do setor primário exportador para o fortalecimento industrial. Infelizmente, não parece ter sido esse o caso do Brasil nos anos 2000, quando o desempenho da indústria brasileira foi pouco satisfatório.

\begin{abstract}
Notas
1 Originalmente as propostas de crescimento wage-led e profit-led (que equivaleria à export-led) foram apresentadas em texto de Bhaduri e Marglin (1990), considerado clássico no assunto por Ferrari Filho e Paula (2015). No primeiro caso, a ideia é que uma mudança na distribuição da renda a favor dos salários é o que sustenta o crescimento. No segundo regime, o crescimento é determinado muito mais pelo crescimento dos lucros em relação às demais rendas.

2 Enquanto Coase (1937) observou que as firmas existem e se organizam justamente para economizar os custos de utilização dos mercados e Williamson (1999) definiu as estruturas de governança criadas para reduzir os Custos de Transação, North (1990, 1994; 1998; 2005) propôs uma análise mais agregada do desempenho, argumentando, a partir da história de desenvolvimento das nações, que os países mais avançados foram justamente aqueles que evoluíram sua estrutura de regras permitindo a ampliação dos mercados, a redução dos custos de transação e avanço da estrutura produtiva.

3 Entre elas estão um sistema financeiro forte (público e privado), uma educação primária e secundária adequada, universidades com formação de cientistas e engenheiros capazes de operar novas tecnologias, laboratórios públicos e privados de P\&D e mecanismos de incentivo à cooperação entre firmas.

${ }^{4}$ Além da dimensão técnica, essa definição de paradigma incorpora uma análise sistêmica e institucional da mudança econômica, demonstrando que instituições e tecnologias devem evoluir conjuntamente durante o processo de crescimento (CONCEIÇÃO, 2001).

${ }^{5}$ Ainda que a taxa de câmbio tenha se mostrado um importante instrumento para consolidação da indústria ao longo do Processo de Substituição de Importações (P.S.I.), o novo desenvolvimentismo afirma que a maioria dos países da América Latina já teria superado a necessidade de protecionismo (tese da "indústria infante"), sendo mais importante uma determinação adequada dos preços macroeconômicos para um crescimento autônomo, puxado pelas exportações.

${ }^{6}$ Bresser-Pereira e Gala (2010) definem a doença holandesa como uma sobreapreciação "crônica da taxa de câmbio", causada pela exploração de recursos naturais abundantes e baratos, gerando rendas ricardianas que valorizam a moeda nacional e impedem a competitividade das indústrias que seriam eficientes na ausência do problema.

${ }^{7}$ Bresser-Pereira et. al. (2014) desenvolveram um estudo empírico para o Brasil demonstrando que a poupança externa substitui a interna porque prejudica os investimentos produtivos via valorização cambial.

${ }^{8}$ Para o novo desenvolvimentismo, o controle de preços se relaciona, em grande medida, com a postura assumida pelo Estado, que deve limitar muito mais seu campo de atuação comparativamente aos momentos em que a estratégia de substituição de importações era prioritária. Ao invés de assumir a responsabilidade pelo desenvolvimento, o setor público deve delegar ao mercado os investimentos prioritários, oferecendo condições macroeconômicas para eficiente alocação de recursos pela iniciativa privada (Bresser-Pereira, 2014a), evitando assim pressões sobre o orçamento e possíveis gastos inflacionários.
\end{abstract}

${ }^{9}$ Carneiro (2012) afirma que as reflexões sobre o social desenvolvimentismo são fragmentadas e com menor inserção acadêmica que as do novo desenvolvimentismo.

10 "Transformação Produtiva com Equidade" (TPE) apareceu entre as prioridades dessa instituição que, mesmo enfocando a importância do setor produtivo, não deixa em segundo plano a necessidade de políticas distributivas (CEPAL, 1990; BIELSCHOWSKY, 2000).

11 Segundo Bastos (2012) teria sido Guido Mantega o precursor na utilização do termo "social desenvolvimentismo" visando diferenciá-lo do antigo ou nacional desenvolvimentismo. 
${ }^{12}$ Para lanoni (2014, p. 1), o social desenvolvimentismo trata-se de "[...] um processo objetivo, apoiado em determinada relação de força entre as classes e frações, cuja lógica interna baseia-se em um modelo de capitalismo no qual o Estado desempenha um papel ativo na economia e tem base social nos trabalhadores do setor formal, subproletariado, excluídos, estratos das classes médias urbanas, camponeses pobres e setores do empresariado produtivo".

${ }^{13}$ As autoras tratam as perspectivas desenvolvimentistas que se delineiam para o Brasil contemporâneo numa perspectiva marxista (desenvolvimentismo precursor, desenvolvimentismo pós-keynesinano e social-desenvolvimentismo).

${ }_{14}$ Para Biancarelli (2013, p. 53) "[...] um desenvolvimentismo desvinculado da redução das enormes desigualdades sociais que marcam a sociedade brasileira não parece adequado - nem muito promissor em termos práticos - no atual contexto".

15 Na mesma linha de raciocínio, Biancarelli (2013) afirma que existe significativo espaço para redução das desigualdades a partir dos investimentos estatais em infraestrutura social (bens de consumo coletivos ou públicos, como educação, saúde, transporte, etc.).

${ }^{16}$ Carneiro (2012) defende que os países asiáticos optaram por um modelo de crescimento baseado nas exportações porque, diferentemente do Brasil, possuíam um mercado interno limitado e base de recursos naturais pobre. -

17 O PIB per capita (a preços constantes de 2013) finalizou a década passada 15\% acima da média de 1990 (IPEA, 2015), a inflação se manteve na meta e as contas externas foram sustentadas pelo volume significativo de reservas (próximas a 300 bilhões de dólares no final dos anos 2000) e pelo efeito China que melhorou o desempenho do setor exportador.

${ }^{18}$ O programa bolsa família, por exemplo, chegou a transferir R\$ 24,5 bilhões de Reais em 2013.

${ }^{19}$ Veja-se, por exemplo, os últimos trabalhos de D. North e seu conceito de Open Access Society (NORTH, WALLIS \&WEINGAST, 2009)

${ }^{20}$ Depois de estar próxima dos 20\% do PIB, em 2016 a taxa de investimento regrediu para uma média pouco superior a 16\% (IPEA, 2016).

${ }^{21}$ A propósito, estudos como os de Gonçalves (2012) e Gentil e Araújo (2012) mostram que o volume de reservas é pouco significativo em relação às dívidas de curto prazo existentes no país.

22 Estudos do Centro de Macroeconomia Aplicada (CEMAP, 2014) da FGV tem demonstrado a magnitude da sobrevalorização cambial. Em 2014, o Real estaria 19\% acima da taxa de equilíbrio de longo prazo. O resultado são déficits crônicos no setor de maior conteúdo tecnológico (PROTEC, 2011).

${ }^{23}$ Yano e Monteiro (2008, p. 7) argumentam que o grande ingresso de capitais se deve a eliminação de barreiras aos investimentos estrangeiros, a entrada de instituições financeiras internacionais (via compra de ações e/ou instalação de subsidiárias) e ao acesso de residentes às novas modalidades de financiamento externo. Em números, a conta capital e financeira passa de um saldo médio anual de 238 milhões na década de 1990 para 847 milhões na década de 2000 (BCB, 2016).

${ }^{24}$ A partir dos estudos de Kaldor, Thirlwall (2005) sintetiza em três leis a importância da indústria no desenvolvimento. Segundo o autor existe forte relação causal entre o crescimento da produção manufatureira e do PIB (1० lei); entre a produção manufatureira e o aumento na produtividade no próprio setor manufatureiro ( $2^{\circ}$ lei, também conhecida como lei de Verdoon) e entre o aumento da produtividade no setor manufatureiro e o crescimento da produtividade fora desse setor ( $3^{\circ}$ lei).

${ }^{25}$ Conforme Carneiro (2008), quando esse indicador declina significa que uma parcela crescente das compras intermediárias se origina fora do setor industrial.

${ }^{26}$ Consideram-se commodities: café, soja, farelo de soja, óleo de soja bruto, suco de laranja, açúcar bruto e refinado, celulose, alumínio, carne suína, bovina e de frango in natura, fumo em folhas, minério de ferro, petróleo bruto, algodão, milho e etanol.

${ }^{27}$ Como ressaltam Cimoli et al (2017): "[...] while social expenditure and direct redistribution are crucial for improving income distribution, sustainable equality requires structural change."

${ }^{28}$ Esta, aliás, teria sido a estratégia de regulação dos anos dourados ao permitir que os ganhos de produtividade do modo fordista fossem absorvidos por políticas keynesianas.

${ }^{29}$ Carneiro (2008) observa que o crescimento do setor produtor de material eletrônico e de comunicações é o que dá suporte ao avanço da tecnologia da informação e suas atividades conexas, que se relacionam com a microeletrônica.

30 Segundo Gonçalves (2012) o social desenvolvimentismo priorizava uma política fiscal expansiva, taxa de juros real negativa, expansão do crédito seletivo e câmbio diferenciado em detrimento da estabilização monetária. 


\section{Referências}

AGLIETTA, M. Régulation et crises du Capitalisme: I'expérience des États-Unis. Paris: CalmannLévy, 1976.

AREND, M. A industrialização do Brasil ante a nova divisão internacional do trabalho. Texto para discussão, Instituto de Pesquisa Econômica Aplicada.- Brasília : Rio de Janeiro: Ipea, 2015.

BASTOS, P.P.Z. Social desenvolvimentismo. E-mail ao professor Bresser-Pereira, 2012. Disponível em: https://bit.ly/31TZNE8. Acesso em: 15 Jan. 2016.

BASTOS, P.P.Z. A economia política do novo-desenvolvimentismo e do social desenvolvimentismo. Revista Economia e Sociedade. Campinas, v. 21, Número Especial, 2012, p. 779-810.

BHADURI. A.; MARGLIN, S. Unemployment and the real wage: the economic basis for contesting political ideologies. Cambridge Journal of Economics, n. 14, p. 375-393, 1990.

BIANCARELLI, A. M. Por Uma Agenda Social-Desenvolvimentista para o Brasil. SP: Fundação Perseu Abramo, 2013.

BIELCHOWSKY, R. (org). Cinqüenta Anos de Pensamento na CEPAL. Rio de Janeiro: Record, 2000.

BIELSCHOWSKY, R. Pensamento Econômico Brasileiro: o Ciclo Ideológico do

Desenvolvimentismo. Rio de Janeiro: IPA/INPES, 1988.

BIELSCHOWSKY, R. Estratégia de desenvolvimento e as três frentes de expansão no Brasil: um desenho conceitual. Revista Economia e Sociedade. Campinas, v. 21, Número Especial. p. 729 747, 2012.

BOYER. R. A teoria da regulação: uma análise crítica. São Paulo: Nobel, 1990.

BRESSER-PEREIRA, L.C. Taxa de câmbio, doença holandesa, e industrialização. Cadernos FGV Projetos, v. 5 , n. 14, p. 68-73, 2010.

BRESSER-PEREIRA, L. C. Estratégia nacional e desenvolvimento. Revista de Economia Política, v. 26, n.2, p. 102, abr./jun. 2006.

BRESSER-PEREIRA, L.C (2007a). Globalização e Estado-Nação. Textos para Discussão n. 17, Fundação Getúlio Vargas. FGV, 2007 a.

BRESSER-PEREIRA, L.C. Macroéconomie développementiste. Palestra no Institut des Amériques, Paris, 2014a.

BRESSER-PEREIRA, L.C. Reflecting on New Developmentalism. São Paulo: EESP/FGV, 2014b.

BRESSER-PEREIRA, L.C. A taxa de câmbio no centro da teoria do desenvolvimento. Revista Estudos Avançados, v. .26, n. 75, p. 5-28, 201 a.

BRESSER-PEREIRA, L.C. Social desenvolvimentismo. E-mail ao professor Pedro Paulo Zahluth Bastos, 2012b. Disponível em: https://bit.ly/2OVY8bP. Acesso: 15 Jan. 2016.

BRESSER-PEREIRA, L.C. National development strategy: the key economic growth institution. Textos para discussão da Escola de Economia de São Paulo, $2007 \mathrm{~b}$.

BRESSER-PEREIRA, L.C. The access to demand. Working Paper n. 366 da Fundação Getúlio Vargas, 2014C.

BRESSER-PEREIRA, L. C; ARAÚJO, E. GALA, P. An empirical study of the substitution of foreign for domestic savings in Brazil. Revista de Economia da ANPEC, v. 15, n. 54-67, 2014.

BRESSER-PEREIRA, L. C; GALA, P (2010). Macroeconomia estruturalista do desenvolvimento. Revista de Economia Política, v. 30, n. 4, pp. 663-686, 2010. 
BRESSER-PEREIRA, L. C; THEUER, D. Um estado novo desenvolvimentista na América Latina? Revista Economia e Sociedade, v. 21, número especial, p. 811 -829, 2012.

BRUNO, M. A. P. Crescimento econômico, mudanças estruturais e distribuição as transformações do regime de acumulação no Brasil: uma análise regulacionista. Tese (Doutorado em Economia) - Universidade Federal do Rio de Janeiro, Rio de Janeiro, 2004.

CANO, W. Desindustrialização no Brasil é real e estrutural. CEDE, 2015. Disponível em: https://bit. ly/2Sr2AS4. Acesso: 1 Dez. 2019.

CARNEIRO, R. M. Velhos e novos desenvolvimentismos. Economia e Sociedade. Campinas, v. 21, Número Especial, p. 749-768, 2012.

CARNEIRO, R. M (2012). (Des)industrialização e desenvolvimento. Teoria e Debate, 2012. Disponível em: https://bit.ly/2uR7mzh. Acesso em: 10 Dez. 2019.

CARNEIRO, R. Impasses do desenvolvimento brasileiro: a questão produtiva. Texto para discussão, n. 153. Campinas: IE/UNICAMP, 2008.

CEMAP. Centro de Estudos em Macroeconomia Aplicada. SP: FGV, 2015.

CEPAL (1990). Transformacion Productiva com Equidad. Santiago: CEPAL.

CHANG, H-J. Chutando a escada: a estratégia de desenvolvimento em perspectiva histórica. São Paulo: Editora da UNESP, 2004

CIMOLI, M.; PORCILE, G.; MARTINS NETO, A.; SOSSDORF, F. Productivity, social expenditure and income distribution in Latin America. Revista de Economia Política, v. 37, n. 4 (149), p. 660-679, 2017.

COASE, R. The nature of the firm: origins, evolution, and development. New York/Oxford: Oxford University, 1937 [1993].

CONCEIÇÃO, O.A.C. Instituições, crescimento e mudança na ótica institucionalista. Porto Alegre: Fundação de Economia e Estatística Siegfried Emanuel Heuser (FEE), 2001.

CORIAT, B; DOSI, G. The institutional embeddedness of economic change: an appraisal of the 'evolutionary' and 'regulationist' research programmes, 2007. Disponível em http://esnie.org/ pdf/textes_2007/Dosi-chap-12.pdf. Acesso 17 Jul. 2013.

COSTA, F.N. Desenvolvimento do desenvolvimentismo: do socialismo utópico ao socialdesenvolvimentismo. Texto para discussão. IE/UNICAMP. Campinas, n. 205, 2012.

COSTA, F.N. Qualificação do Desenvo.lvimentismo. Brasil Debate, 2015. Disponível em https://bit. ly/2wsKAhE. Acesso: 23 Fev. 2015.

CURADO, M. Por que o governo Dilma não pode ser classificado como novodesenvolvimentista?. Revista de Economia Política, v. 37, n. 1, p.130-146, 2017.

DENZAU, A.; NORTH, D (1994). Shared mental models: ideologies and institutions. Kylos, v. 47, n. 1, p. 3-31. Disponível em: https://bit.ly/2VLKJHE. Acesso: 19 Dez. 2011.

FAJNZYLBER, F (2000). Industrialização na América Latina: da "caixa-preta" ao "conjunto vazio". In: BIELSCHOWSKY, R. (org.), Cinquenta anos da CEPAL, Santiago de Chile: CEPAL.

FERRARI FILHO, F.; PAULA, L.F (2015). Padrões de crescimento e desenvolvimentismo: uma perspectiva keynesiano-institucionalista. Nova Economia, v. 26, n. 3, p. 775-807. Disponível em https://bit.ly/38timBn. Acesso: 14 Mar. 2016.

FONSECA, P. C. D. Desenvolvimentismo: a construção do conceito. In CALIXTRE, A. B.; BIANCARELLI, A. M., CINTRA, M. A. M. (eds). Presente e Futuro do Desenvolvimento Brasileiro. Rio de Janeiro: IPEA, p. 29-78, 2014. 
FREEMAN, C; PÉREZ, C. Structural Crises of Adjustment, Business Cycles and Investment Behaviour. In: G. Dosi et al. (eds.). Technical Change and Economic Theory. London: Francis Pinter, 1988.

FURTADO, C. Os Desafios da Nova Geração. Revista de Economia Política, v. 24, n. 4 (96), outubrodezembro, 2004.

GONÇALVES, R (2012). Governo Lula e o Nacional-Desenvolvimentismo às Avessas. Revista da Sociedade Brasileira de Economia Política, n. 31.

GONÇALVES. R. Novo Desenvolvimentismo e Liberalismo Enraizado. Revista Serviço Social \& Sociedade, n. 112, p. 637-671, 2012.

GENTIL, D.L.; ARAÚJO, V. L. Dívida Pública e Passivo Externo. Onde Está a Ameaça? Texto para discussão, n. 1768. Rio de Janeiro: IPEA, 2012.

HODGSON. G. M. Choice, Habit and Evolution. Journal of Evolutionary Economics, v. 20, n. 1, p. 1-18, January 2010.

.What Are Institutions? Journal of economic issues, v. XL, n; 1, p. 1-25, 2006.

IANONI, M (2014). Qual desenvolvimentismo? Jornal do Brasil. Disponível em https://bit. ly/2HnAocm. Acesso: 23 Fev. 2016.

KERSTENETZKY, C. L. Consumo e Crescimento Redistributivo: Notas para se pensar um modelo de crescimento para o Brasil. Texto para discussão, n. 106, junho de 2015. Center for Studies on Inequality and Development. CEDE.

KUHN, T. S. A estrutura das revoluções científicas. Tradução de Beatriz Vianna Boeira e Nelson Boeira. 3.ed. São Paulo: Perspectiva, 1992.

KREIN, J. D. As mudanças institucionais e as relações de trabalho no Brasil após o Plano Real, 2001. Campinas. Disponível em: https://bit.ly/39BOovu. Acesso em: 07 nov. 2010.

MANTEGA, G. Entrevista Roda Viva. 03.12.2007. Disponível em: https://bit.ly/38Fphal. 2007b.

MAZZUCATO, M. O Estado empreendedor: desmascarando o mito do setor público vs. setor privado. São Paulo: Portfolio-Penguin, 2014.

MOLLO, M.L.R.; AMADO, A.M. O debate desenvolvimentista no Brasil: tomando partido. Revista Economia e Sociedade, v. 24, n. 1(53), p. 1-28. Campinas, Jan./Apr. 2015.

NELSON, R. R. Economic Development from the perspective of evolutionary economic theory. Working paper series: Globelics, 2007.

NELSON, R. R.; SAMPAT, B.N. Las instituiciones como factor que regula el desempeño econômico. Revista de economia institucional, Bogotá, v. 2 n. 5, 9 17-51, 2001.

NORTH, D.C. Custos de transação, instituições e desempenho econômico. Rio de Janeiro: Instituto Liberal, 1994.

. Desempeño económico en el transcurso de los años. Estocolmo, 1998. Disponível em: https://bit.ly/2VJVwIN. Acesso em: 17 Fev. 2009.

. Institutions, institutional change and economic performance. Cambridge: Cambridge

University Press, 1990.

. Understanding the process of economic change. Princeton/Oxford: Princeton University Press, 2005.

NORTH, D., WALLIS, J.; WEINGAST, B. Violence and Social Orders: A Conceptual Framework for Interpreting Recorded Human History. Cambridge: Cambridge University Press, 2009.

OREIRO, J.L. FEIJÓ, C.A (2010). Desindustrialização: conceituação, causas, efeitos e o caso brasileiro. Revista de Economia Política, v. 30, n. 2 (118), p. 219-232, abril-junho 2010. 
OREIRO, J. L. Estagnação com pleno emprego. Valor Econômico. Publicado em 27 Dez. 2012.

OREIRO, J, L.; MARCONI, N. O Novo-Desenvolvimentismo e Seus Críticos. Cadernos do Desenvolvimento. Rio de Janeiro, v. 11, n. 19, p.167-179, jul.-dez, 2016.

PEREIRA, A. J.; DATHEIN, R. Política industrial como instituição desenvolvimentista: uma crítica ao "novo desenvolvimentismo" baseada nas experiências de brasil e coreia do sul. Revista de economia contemporânea, v. 20, n.1, p.28-57, 2016.

PEREZ, C. Cambio técnico, restructuración competitiva y reforma institucional en los países en desarrollo. El trimestre económico, México, v. 1, n. 233, p. 23-64, enero/marzo, 1992. . Cambio tecnológico y oportunidades de desarollo como Blanco móvil. Revista de la CEPAL, Santiago de Chile, n. 75, p. 115-136, 2001.

POCHMANN, M. Do neoliberalismo ao social-desenvolvimentismo. Revista Fórum, 2012. Disponível em: https://bit.ly/38tDJTI. Acesso: 07 Mar. 2016.

TEN THESES ON NEW DEVELOPMENTALISM. Disponível em http://www.tenthesesonnewdevelopmentalism.org. Acesso: 30 Jun. 2014.

PROTEC. Pró-inovação tecnológica. Monitor do Déficit Tecnológico, 2011. Disponível em https:// bit.ly/38vmFfD. Acesso: 01 Dez. 2015.

THIRLWALL (2005). A. P. A Natureza do Crescimento Econômico: um referencial alternativo para compreender o desempenho das nações. Brasília, IPEA, 2005.

SCHUMPETER, J. A. Capitalismo socialismo e democracia. Rio de janeiro: Fundo de Cultura, 1942 [1984].

SCHUMPETER, J. A (A Teoria do desenvolvimento econômico. São Paulo: Nova Cultural, 1911 [1985].

UNIDO. United Nations Industrial Development Organization, 2016. Disponível em http://www. unido.org/. Acesso 05 Jan. 2017.

VEBLEN, T. Why is economics not an evolutionary science?. Quarterly Journal of Economics. V. 12, n. 4, p. 373-397, 1898.

The place of science in modern civilization and other essays. New York : Huebsch, 1919.

WILLIAMSON, O. E. The economics and transaction costs. New York: Free Press, 1999.

YANO, N. M.; MONTEIRO, S. M. M. Mudanças institucionais na década de 1990 e seus efeitos sobre a produtividade total de fatores. In: ENCONTRO NACIONAL DE ECONOMIA, 36., 2008, Salvador. Anais do XXXVI Encontro Nacional de Economia. Disponível em: https://bit.ly/38ukfoU. Acesso em: 10 Jan. 2010.

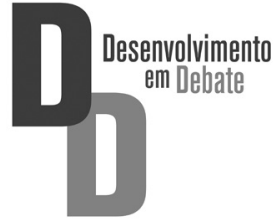

